\title{
Electrochemical Synthesis of NiAu Bimetallic Nanostrips and Their Application for Hydrazine Detection
}

\author{
Lin-Lin Hou, Ye Wan, Jia-Yin Li, Jun-Rui Zhang, Keying Cui, Su-Juan Li ${ }^{*}$ \\ Henan Province Key Laboratory of New Optoelectronic Functional Materials, College of Chemistry \\ and Chemical Engineering, Anyang Normal University, Anyang, 455000, Henan, China \\ *E-mail: lemontree88@163.com
}

doi: $10.20964 / 2019.06 .55$

Received: 13 February 2019 / Accepted: 28 March 2019 / Published: 10 May 2019

\begin{abstract}
$\mathrm{NiAu}$ bimetallic nanostrips with nearly monodispersed structure were synthesized through a one-step electrodeposition method with cetyltrimethylammonium bromide (CTAB) involved as the stabilizer and $\mathrm{Ni}\left(\mathrm{NO}_{3}\right)_{2}$ and $\mathrm{HAuCl}_{4}$ with a molar ration of $1: 1$ as the precursor. The morphology of as-prepared $\mathrm{NiAu}$ bimetallic nanomaterials with different $\mathrm{Ni} / \mathrm{Au}$ molar rations were characterized with scanning electron microscopy (SEM). The resultant NiAu bimetallic nanostrips showed good electrocatalytic activities toward hydrazine oxidation. Various parameters including $\mathrm{Ni} / \mathrm{Au}$ molar rations, CTAB concentration and solution $\mathrm{pH}$ affecting the performance of $\mathrm{NiAu}$ bimetallic nanomaterials toward hydrazine detection were investigated. Under optimized conditions, NiAu bimetallic nanostrips based electrochemical hydrazine sensor has a linear response in the concentration range of 0.5 to $1665 \mu \mathrm{M}$, a lower detection limit of $0.1 \mu \mathrm{M}$ and high detection sensitivity $\left(1007 \mu \mathrm{AmM}^{-1} \mathrm{~cm}^{-2}\right)$. Most common ions and many environmental organic species do not interfere with the detection of hydrazine.
\end{abstract}

Keywords: Bimetallic nanostrip; Electrodeposition; Hydrazine; Nickle; Gold

\section{$\underline{\text { FULL TEXT }}$}

(C) 2019 The Authors. Published by ESG (www.electrochemsci.org). This article is an open access article distributed under the terms and conditions of the Creative Commons Attribution license (http://creativecommons.org/licenses/by/4.0/). 